\title{
A transferência na relação analítica: um retorno a Freud e Ferenczi
}

\section{The transference in analytical relationship: a return to Freud and Ferenczi}

Fernanda Barros Moreira ${ }^{1}$

Resumo

O objetivo deste artigo foi fazer um estudo bibliográfico a partir dos textos de Freud e de Ferenczi sobre o fenômeno da transferência na relação analítica, destacando a importância desta como possibilidade de transformação. A transferência possibilita ao paciente reviver afetos inconscientes e, quando a resistência for superada, abre-se uma possibilidade de mudanças profundas. Para Freud, na transferência, o material reprimido pode se tornar consciente, desde que as resistências sejam quebradas. Para Ferenczi, o analista deve dosar a tensão e o desprazer do processo analítico conforme a estrutura do ego do paciente, dando a este o tempo necessário para superar suas resistências. Ambos os autores salientam a dificuldade do manejo da transferência no processo analítico e a importância da análise do psicanalista. A partir da sua própria análise, o analista poderá ocupar a função de espelho essencial no processo de análise.

Palavras-chave: Psicanálise. Transferência. Psicanalista.

\begin{abstract}
The aim of this article was to study the transference phenomenon in the analytic relationship, highlighting its importance as a possibility of transformation, based on the texts of Freud and Ferenczi. The transference allows the patient to update unconscious affects, and when the resistance is overcome, a possibility of profound changes appears. According to Freud, in the transference process, the repressed material can become conscious, as long as the resistances are broken. For Ferenczi, the analyst must measure the tension and displeasure of the analytic process according to the structure of the patient's ego, giving the patient the necessary time to overcome his resistances. Both the authors highlight the difficulty of the transference management in the analytical process and the importance of the psychoanalyst's personal analysis. From his own analysis, the analyst can occupy the role of the mirror, essential in the analysis process.
\end{abstract}

Keywords: Psychoanalysis. Transference. Psychoanalyst.

\footnotetext{
${ }^{1}$ Doutora em Produção Animal pela Universidade Estadual de Maringá. Atualmente psicóloga clínica em consultório particular. E-mail: ferbarrosmoreira@gmail.com
} 


\section{Introdução}

No processo analítico, analista e analisando se encontram, em uma relação entre duas pessoas, onde existem dois inconscientes, do analista e do analisando, e dois sujeitos, com suas respectivas histórias, resistências, complexos, sentimentos. Nesta relação, a busca é por conhecer o inconsciente do analisando, como forma de amenizar sua dor psíquica.

A partir da regra fundamental da análise: associação livre do analisando e escuta flutuante do analista, algo do inconsciente pode aparecer para ser decifrado. A transferência, um fenômeno que se manifesta também no campo analítico, pode representar uma possibilidade de transformação ou uma interrupção no processo analítico, a depender do destino que a dupla dá ao fenômeno.

A partir do estudo das obras de Freud e de Ferenczi, o objetivo deste artigo é discutir como estes psicanalistas entendiam o fenômeno da transferência, para ajudar a compreender possíveis desdobramentos na técnica da clínica psicanalítica.

\section{A Transferência na Relação Analítica}

Nas relações intersubjetivas, investimentos pulsionais, também nomeados de afeto, achamse presentes desde o início. Para Freud (1996a), existem duas formas de investimento pulsional. Uma parte deles é consciente, dirigida para a realidade e a personalidade consciente faz uso desta parte da pulsão nos diversos relacionamentos. Ao mesmo tempo, existe outra parte de investimento pulsional, ligado a ideias reprimidas, retidas e impedidas de chegarem ao sistema consciente, portanto inconscientes, que se afasta da realidade e busca satisfação a partir da fantasia. Estes impulsos ligados a ideias reprimidas estão fora da consciência, mas estão presentes nas maneiras como o indivíduo estabelece relações afetivas. Assim, a cada nova aproximação de se relacionar com outras pessoas, já estarão presentes ideias antecipadas, decorrentes de investimentos pulsionais inconscientes. A este fenômeno, Freud nomeia de transferência e reforça que é um processo universal, presente em todas as relações humanas.

Freud (1996d) destaca a importância da transferência no processo analítico, de um lado, como um instrumento de alto valor e, de outro, uma fonte de sérios perigos. No mesmo artigo de 1940, ele relembra a questão da ambivalência dos afetos, de forma que os sentimentos de afeição (positivos), assim como hostis ou eróticos (negativos) são transferidos para o analista. Quando a transferência é positiva, ela é útil ao analista, pois o paciente irá agradá-lo com o objetivo de conquistar seu aplauso e amor. Por outro lado, como as relações são ambivalentes, a transferência também irá se manifestar de forma ambivalente e, neste momento, pode aparecer uma ocasião para a mudança. Se, na transferência positiva, suspeita-se que parte da melhora do paciente seja de natureza sugestiva, e, portanto, temporária; na transferência negativa abrese uma possibilidade de acessar o que o material mais oculto inconsciente. Segundo Freud,

\begin{abstract}
Não se discute que controlar os fenômenos da transferência representa para o psicanalista as maiores dificuldades; mas não se deve esquecer que são precisamente eles que nos prestam o inestimável serviço de tornar imediatos e manifestos os impulsos eróticos ocultos e esquecidos do paciente. Pois, quando tudo está dito e feito, é impossível destruir alguém in absentia ou in effigie. (FREUD, 1996a, p. 119).
\end{abstract}

A transferência abre a possibilidade de o paciente representar para o analista a sua história, não apenas relatando o que viveu, mas revivendo novamente os afetos sentidos em fase anterior, como uma forma de atualizar os impulsos eróticos ocultos. Neste reviver, se as resistências forem superadas, abrese uma possibilidade de mudanças profundas, pois permite uma nova compreensão das demandas de amor. Para Kupermann (2008), a transferência; sua 
instalação, manejo e destino; passa a ser o modus operandi da clínica.

Em análise, a comunicação entre analista e analisando pode ocorrer e, neste processo, o fenômeno transferencial ganha papel preponderante. Freud (1996e) destaca que pode haver comunicação entre o inconsciente de pessoas diferentes sem que haja a passagem pelo sistema consciente e, esta possibilidade de comunicação influencia o processo analítico, já que a análise é fundada na comunicação entre paciente e analista. Ferenczi (2011d) também chama a atenção para a comunicação entre inconscientes. Ele destaca a importância da sinceridade do analista e de sua análise pessoal, uma vez que o paciente é capaz de perceber os mais variados afetos do analista, mesmo os inconscientes, além de seus pensamentos e emoções. Pontes e Torrano (2010) comparam a comunicação inconsciente com o modelo Bluetooth, onde para que ocorra a comunicação sem fio, é preciso que os dispositivos sejam compatíveis, permitindo que um dispositivo detecte o outro, dentro de um limite de proximidade.

Por isso que Freud, em vários de seus artigos, destaca a importância da transferência e de seu manejo no processo analítico. Em 1914, no artigo Recordar, Repetir e Elaborar descreve que o objetivo da análise é superar as resistências devido à repressão. Destaca que existem casos em que o paciente não consegue se recordar do material que foi reprimido, mas, ao invés disso, expressa o reprimido a partir da atuação. Esta repetição seria a sua maneira de recordar. Repete, na vida atual e na relação com o analista, os seus sintomas, suas inibições, seus traços patológicos de caráter (FREUD, 1996h).

O que está em questão é uma força atual e não apenas um acontecimento do passado. A partir desta observação, Freud se questiona sobre a possibilidade de se correlacionar a compulsão à repetição com a transferência e com a resistência. Ele percebe que a transferência é um fragmento da repetição e quanto maior for a resistência, mais extensivamente a atuação substituirá o recordar.

Segundo Freud,

A transferência cria, assim, uma região intermediária entre a doença e a vida real, através da qual a transição de uma para outra é efetuada. A nova condição assumiu todas as características da doença, mas representa uma doença artificial, que é, em todos os pontos, acessível à nossa intervenção. Trata-se de um fragmento de experiência real, mas um fragmento que foi tornado possível por condições especialmente favoráveis, e que é de natureza provisória. A partir das reações repetitivas exibidas na transferência, somos levados ao longo dos caminhos familiares até o despertar das lembranças, que aparecem sem dificuldade, por assim dizer, após a resistência ter sido superada. (FREUD, 1996h, p. 170).

Para que o analisando supere suas resistências, é importante que o analista vá as revelando aos poucos, dando tempo suficiente para que este possa se familiarizar com as mesmas e, num próximo passo, poder elaborá-las. Uma revelação precoce pode resultar em um aumento da resistência e não sua superação.

"Esta elaboração das resistências pode, na prática, revelar-se uma tarefa árdua para o sujeito da análise e uma prova de paciência para o analista. Todavia, trata-se da parte do trabalho que efetua as maiores mudanças no paciente e que distingue o tratamento analítico de qualquer tipo de tratamento por sugestão". (FREUD, 1996h, p. 171).

Ferenczi (2011a) propõe ao analista permanecer passivo perante as manifestações da transferência. Para Ferenczi, assim como para Freud, não se deve responder às exigências do paciente como também não se deve recorrer à moral. A saída seria acolher a manifestação do paciente e indicar repetidamente a natureza transferencial da conduta. Mas, ao mesmo tempo, o analista deve saber respeitar o tempo do paciente, pois não é a explicação do analista que 
possibilitará trazer à consciência o inconsciente, mas sim as próprias forças psíquicas do paciente que serão capazes de tal processo. Cabe ao analista exercitar as forças psíquicas do paciente, quebrando as resistências.

A situação do médico no tratamento psicanalítico lembra, sob muitos aspectos, o do obstetra, que também deve, tanto quanto possível, comportarse passivamente, limitar-se ao papel de espectador de um processo natural, mas que, nos momentos críticos, terá o fórceps ao alcance da mão para terminar um nascimento que não progrida espontaneamente. (FERENCZI, 2011a, p. 412)

\section{O Manejo da Transferência}

No processo analítico, afetos são revividos e a repetição destes afetos, agora no setting, constitui importante instrumento para que a análise prossiga. Se existem forças poderosas atuando, afetos sendo transferidos, logo suspeita-se da dificuldade e do comprometimento necessário à dupla para que o trabalho na transferência possa ser realizado. Freud (1996f), em Observações sobre o amor transferencial, já salienta que as únicas dificuldades realmente sérias no processo terapêutico é o manejo da transferência.

Todo principiante em psicanálise provavelmente se sente alarmado, de início, pelas dificuldades que lhe estão reservadas quando vier a interpretar as associações do paciente e lidar com a reprodução do reprimido. Quando chega a ocasião, contudo, logo aprende a encarar estas dificuldades como insignificantes e, ao invés, fica convencido de que as únicas dificuldades realmente sérias que tem de enfrentar residem no manejo da transferência. (FREUD, 1996f, p. 177.)

Em relação ao amor de transferência, Freud (1996f) destaca que a visão do analista deve ser diferente da visão do leigo. Para este, quando um paciente enamora-se do seu médico, existem apenas três desfechos: paciente e médico assumem o relacionamento e vive este "grande amor"; médico e paciente se separam e interrompem o trabalho que começaram; iniciam um relacionamento amoroso ilícito e, mais cedo ou mais tarde, acabam por rompê-lo.

Esta é a visão do leigo, mas o analista tem na transferência a ferramenta de seu trabalho. Freud (1996f) destaca que o analista não deve responder ao amor do paciente, mas também não deve suprimi-lo. O analista deve saber que está diante de um fenômeno valioso e reconhecer que estes afetos são decorrentes do próprio processo analítico e não um encantamento em relação à pessoa do analista.

É, portanto, tão desastroso para a análise que o anseio da paciente por amor seja satisfeito, quanto que seja suprimido. O caminho que o analista deve seguir não é nenhum destes; é um caminho para o qual não existe modelo na vida real. Ele tem de tomar cuidado para não se afastar do amor transferencial, repeli-lo ou torná-lo desagradável para a paciente; mas deve, de modo igualmente resoluto, recusar-lhe qualquer retribuição. (FREUD, 1996f, p. 183)

No mesmo artigo, Freud (1996f) destaca que certas pessoas, sem citar autores específicos, recomendariam retribuir os sentimentos amorosos do paciente, evitando o contato físico que estes sentimentos poderiam levar. No entanto, ele não concorda com tal recomendação por dois motivos: um é a questão da sinceridade, que é fundamental para o processo analítico; outro ponto é o perigo que isto pode resultar, já que o analista também não possui total controle sobre si mesmo, a ponto de eventualmente ir além do que planejava. Por isso, Freud salienta sua posição de neutralidade e, para isso, a necessidade de manter controlada a contratransferência.

Já deixei claro que a técnica analítica exige do médico que ele negue à paciente que anseia por amor a satisfação que ela exige. $\mathrm{O}$ tratamento deve ser levado a cabo na abstinência. Com 
isto não quero significar apenas a abstinência física, nem a privação de tudo o que a paciente deseja, pois talvez nenhuma pessoa enferma pudesse tolerar isso. Em vez disso, fixarei como princípio fundamental que se deve permitir que a necessidade e anseio da paciente nela persistam, a fim de poderem servir de forças que a incitem a trabalhar e efetuar mudanças, e que devemos cuidar de apaziguar estas forças por meio de substitutos. (FREUD, 1996f, p. 182).

Na clínica, a manifestação da transferência abre uma possibilidade para que o fenômeno possa ser entendido, decifrado, a partir da interpretação e da construção do par analítico. O que se está repetindo na transferência são os fantasmas inconscientes, vividos de forma intensa, já que estão investidos de catexias poderosas e estão ali postos como uma oportunidade para serem decifrados, serem descobertos. Por isso é tão complexo. Ambos do par analítico (analista e analisando) estão implicados no processo, com as respectivas forças inconscientes.

Sándor Ferenczi, durante sua vida profissional, buscou modificar sua técnica para que a dupla pudesse desenvolver a transferência de forma favorável ao tratamento. Ele acreditava que o analista deveria dosar a tensão e o desprazer do processo analítico conforme a estrutura do ego do paciente, até onde este pudesse aguentar. Com este tema, o autor desenvolveu importantes artigos, como Adaptação da família à criança e Análises de crianças com adultos (FERENCZI, 2011b, 2011c).

Freud (1996f) destaca a importância de se trabalhar, em análise, o afeto que se manifesta no campo transferencial. Para ele, estas forças precisam ser trabalhadas e não negadas.

"O psicanalista sabe que está trabalhando com forças altamente explosivas e que precisa avançar com tanto cautela e escrúpulo quanto um químico. Mas quando foram os químicos proibidos, devido ao perigo, de manejar substâncias explosivas, que são indispensáveis, por causa de seus efeitos? " (FREUD, 1996f, p. 187).
Freud (1996b), em Além do Princípio do Prazer, destaca a importância da compulsão à repetição no processo analítico. Neste sentido, a psicanálise não seria apenas a interpretação do inconsciente, mas a reviver destes afetos na transferência. De quais afetos o autor está falando? São os afetos eróticos, de amor e de ódio, que se apresentam na análise em busca de uma significação.

Freud (1996e) também destaca a importância da palavra para que se desenvolva o processo secundário do pensamento. Segundo ele, somente a partir da nomeação do objeto é que será possível transpor o conteúdo para a consciência. Para isso, é necessária a apresentação da coisa mais a apresentação da palavra relacionada à coisa. Enquanto houver somente a apresentação da coisa, esta irá manter-se no inconsciente.

Ferenczi (2011e) propõe o tato psicológico do analista, o "sentir com" como recurso técnico. Para ele, somente após o analista ter dissecado seu próprio eu, ele será capaz de perceber as associações do paciente e saberá a hora e a forma de comunicar isto ao paciente sem estimular a resistência do mesmo, possibilitando ao paciente suportar seu sofrimento. O "sentir com" não significa deixar-se guiar só pelos sentimentos; ao contrário, significa retirar por um momento a libido do paciente para avaliar a situação e somente depois, fazer a comunicação ao paciente. Segundo Ferenczi),

Adquiri a convicção de que se trata, antes de tudo, de uma questão de tato psicológico, de saber quando e como se comunica alguma coisa ao analisando, quando se pode declarar que o material fornecido é suficiente para extrair dele certas conclusões; em que forma a comunicação deve ser, em cada caso, apresentada; como se pode reagir a uma reação inesperada ou desconcertante do paciente; quando se deve calar e aguardar outras associações; e em que momento o silêncio é uma tortura inútil para o paciente, etc. Como se vê, com a palavra "tato" somente consegui exprimir a indeterminação numa fórmula simples e agradável. Mas o que é o tato? A resposta a esta 
pergunta não nos é difícil. O tato é a faculdade de "sentir com" (Einfühlung). (FERENCZI, 2011e, p. 31).

Para Ferenczi (2011e), o analista deve estar aberto às manifestações inconscientes do paciente e ser capaz de falar sobre tais manifestações, não como um professor ou como um médico autoritário, mas como um "João teimoso", onde o paciente exercita seus afetos negativos, sem que o analista se defenda de tais situações. Ao contrário, este deve aguardar pacientemente até que o paciente seja capaz de interpretar, por ele próprio, a situação. Para conseguir isto, o analista deve ter um controle do seu próprio narcisismo e uma vigilância constante das reações afetivas que são provocadas nele. Vale salientar que a única pretensão do processo de "sentir com" é a total sinceridade e franqueza do analista. $\mathrm{O}$ objetivo é resolver as resistências do paciente, pois quando diminuídas, o próprio paciente é capaz de interpretar quase sozinho o conteúdo.

Ferenczi (2011e) propõe o termo elasticidade da técnica, pois o analista deveria atuar como uma tira elástica, capaz de ceder às tendências do paciente sem abandonar a tração em suas próprias opiniões. Para isso, é fundamental o controle do narcisismo do analista, para que seu autoconhecimento e seu autocontrole adquiridos em sua própria analise permitam ao paciente superar suas próprias resistências. O resultado desta elasticidade seria uma economia nas interpretações e a quebra da resistência do paciente, para que, a partir daí, o próprio paciente possa fazer sua interpretação. Segundo Ferenczi (2011e, p. 36), "É preciso aguardar pacientemente que o doente tome a decisão; toda a impaciência por parte do médico custa ao doente tempo e dinheiro, e ao médico uma quantidade de trabalho que teria perfeitamente podido evitar".

Ferenczi (2011e) propõe que o analista deve promover um relaxamento para que o encontro com a experiência inconsciente possa acontecer. Neste encontro, o analista não vai falar da criança, mas sim com a criança, através do lúdico e da linguagem da ternura. Para Kupermann (2008), o princípio da associação livre, abstinência e interpretação poderia ser substituído pelo princípio da associação livre, da regressão e do jogo. $\mathrm{O}$ analista permite que o lúdico entre em cena, aguardando que o paciente possa fazer sua própria interpretação.

Outro ponto que Ferenczi (2011e) chama a atenção é sobre uma possível confusão entre ternura ou erotismo infantil com paixão ou erotismo adulto. Ele esclarece que a criança brinca, de forma lúdica, de ocupar o lugar do progenitor do mesmo sexo, mas isso se dá no plano da fantasia, sem dispensar a ternura materna. This (1995), ao fazer uma introdução sobre a obra de Sándor Ferenczi, salienta a importância de não confundir a ternura infantil e a carícia erotizante do adulto.

Mas não confundamos a ternura com a carícia. A ternura é a antítese de qualquer estimulação erotizante. [Storgeh em grego, é ternura, e 'Stergo' significa que amo ternamente. Esse verbo, 'Stergo', constrói-se a partir do 'Stereous', que quer dizer, em grego, o real, aquilo que é firme e sólido. A ternura, isto é, o amor dos pais, representa para os gregos aquilo que torna firme, que dá firmeza e segurança. (THIS, 1995, p. 85).

Por outro lado, se este brincar é visto por um adulto como uma possível relação de amor, com características do erotismo adulto, isso poderá resultar em um sentimento de culpa intenso, o que introduz o elemento sadomasoquista na sexualidade da criança. A criança se identifica com o agressor e submete-se a ele. Nestas condições, sua vida sexual não se desenvolve ou assume formas perversas. É por isso que Ferenczi (2011d) destaca a importância de não confundir a linguagem da criança com a linguagem do adulto, pois antes de sentir um amor pelo objeto, a criança passa pelo estágio da identificação, ao que Ferenczi nomeia de amor

${ }^{2}$ João teimoso, referência ao boneco que sempre quando empurrado retorna ao lugar de origem. 
objetal passivo, ou estágio da ternura. Somente depois deste estágio é que a criança estará apta para um amor objetal característico do adulto. Segundo o autor,

Os pais e os adultos deveriam aprender a reconhecer, como nós, analistas, por trás do amor de transferência, submissão ou adoração de nossos filhos, pacientes, alunos, o desejo nostálgico de libertação desse amor opressivo. Se ajudarmos a criança, o paciente ou o aluno a abandonar essa identificação e a defender-se dessa transferência tirânica, pode-se dizer que fomos bem sucedidos em promover o acesso da personalidade a um nível mais elevado. (FERENCZI, 2011d, p. 119).

Assim, Ferenczi propõe novas técnicas no processo terapêutico, com o analista presente de forma sincera e benevolente, capaz de "sentir com" o paciente, ao mesmo tempo em que pensa sobre o que sente. $\mathrm{O}$ analista estaria disponível para amar o paciente, em seu sentido de ternura, respeitando o tempo de cada paciente. Segundo Sanches (1994, p. 54),

Ferenczi referia-se, portanto, a uma efetiva capacidade de amar os pacientes, a uma verdadeira disponibilidade afetiva, a uma possibilidade de entrar no mundo do outro sentindo suas alegrias e prazeres, mas também seus tormentos, angústias e desesperos, sem, contudo, precisar recorrer à teoria como escudo protetor, e, ainda assim, sem se perder no outro. Ele se referia a um amor maduro - próprio de organizações psíquicas integradas - que tolera avanços e recuos e que libera o paciente para crescer como, em que ritmo, e para onde puder e quiser.

Resnik (1989) também destaca o quão delicado é falar sobre a sexualidade infantil com uma criança, pois caso a capacidade do jogo e da sublimação não estiver muito bem estabelecida, corre-se o risco de confundir a linguagem infantil com a linguagem do adulto, resultando assim num efeito negativo. Por isso é fundamental a análise do analista.
Para This (1995), Ferenczi enfatizou que a relação analítica se assemelha à situação infantil vivida pelo paciente, por isso se favorece a repetição. Quando a situação analítica abre a possibilidade do paciente reviver o trauma, agora de forma diferente, então este contraste favorece a rememoração.

Ferenczi (2011c) descreve seu método como o de um adulto que mima a criança, sacrificando o próprio conforto em prol do paciente. Nestas condições, o analista deve ceder tanto quanto possível aos desejos e impulsos afetivos, para que o paciente possa mergulhar nos estágios precoces do amor de objeto passivo. Até o momento em que a frustração não tem mais como ser evitada. A criança, agora se sentindo abandonada, perde o prazer de viver ou volta toda a agressão a sua própria pessoa, o que irá exigir muitos esforços e tato por parte do analista, para que a reconciliação seja refeita. O analista vive, no setting terapêutico, a relação de objeto ambivalente, característica da primeira infância. O analista se torna, pela transferência, o objeto de amor e de ódio do paciente, o que é próprio do fenômeno da transferência.

Neste sentido, o analista não está presente apenas para interpretar o inconsciente. Ferenczi vai propor um reviver com o paciente, representando, pela transferência, seus primeiros objetos de amor, dotados de intensa ambivalência. Segundo Fédida (1988, p. 27),

Eis aí uma dificuldade, um paradoxo: nesse caso difícil, a transferência do paciente sobre o terapeuta e a do terapeuta sobre o paciente, traz a esperança de uma reconstrução pelo delírio. Mas essa situação pode também levar ao fracasso do tratamento principalmente porque o terapeuta não pode suportar ser ele próprio objeto da parte do paciente - objeto de amor ou de morte.

Diante do dilema, Fédida (1988) propõe algumas reflexões. Primeiro, o analista precisa reconhecer que o afeto está presente. Dizer que o afeto não é real, ou que ele se dirige a outra pessoa é o mesmo 
que entrar no papel de sedutor, ou seja, aquele que desperta o afeto e depois diz que não tem nada a ver com isso. Se eu, terapeuta, estou implicado no processo, admitindo a presença do afeto, então insiro a situação no tratamento, permitindo uma circulação deste afeto na medida em que abro uma possibilidade para este afeto ser nomeado.

Outro ponto importante destacado por Fédida (1988) é diferenciar o reconhecer o afeto e o responder ao amor. Quando se responde ao amor de transferência, não está se respondendo a ele, mas a outro, ou seja, ao próprio fantasma do analista, não sendo, portanto, verdadeiro para o analisando. No entanto, quando o amor não é correspondido surge a dúvida e a partir deste questionamento é que aparece a possibilidade de criar um sentido. A partir de palavras e gestos vindos do paciente é que pode iniciar um reconhecimento e uma recriação de sentido. A resposta ao pedido de amor do paciente impede a vinda do desconhecido. A não-resposta é que permite o pensar junto.

\section{A Análise do Analista}

Freud (1996c), no artigo Análise terminável e Interminável, se questiona como será possível adquirir as qualificações de um bom analista. A resposta dele é que isso só é possível a partir da análise do analista. Análise esta que não se esgota depois de certo período de tempo, mas que deve sempre estar presente na vida do analista. Para Freud (1996c), a análise do analista deveria se transformar de uma tarefa terminável para uma tarefa interminável.

Todo analista deveria periodicamente - com intervalos de aproximadamente cinco anos submeter-se mais uma vez à análise, sem se sentir envergonhado por tomar essa medida. Isso significaria, portanto, que não seria apenas a análise terapêutica de seus pacientes, mas sua própria análise que se transformaria de tarefa terminável em interminável. (FREUD, 1996c, p. 266).
Ferenczi (2011f) destaca que o paciente, muitas vezes, testa a confiabilidade de seu analista, observando qualquer reação deste, principalmente as inconscientes. $\mathrm{O}$ paciente comporta-se como uma criança birrenta, mas que esconde uma exigência de amor e de ternura. Cabe ao analista uma benevolência e uma paciência para com o paciente, o que só é possível quando o mesmo terminou sua própria análise. Segundo Ferenczi (2011f, p. 24),

\begin{abstract}
Gostaria de completar essa proposição no sentido de que nem sempre é necessário, na prática clínica, aprofundar o tratamento até o ponto que chamamos término completo da análise; em contrapartida, o analista, de quem depende o destino de tantos seres, deve conhecer e controlar até as fraquezas mais escondidas de sua própria personalidade, o que é impossível sem uma análise inteiramente terminada.
\end{abstract}

Ferenczi (2011e), em seu artigo Elasticidade da técnica, alerta para o uso errôneo que alguns analistas poderiam fazer do tato, ou do "sentir com". Ele sabia que, sob o argumento da elasticidade da técnica, poderia se justificar o uso da intuição e da subjetividade do analista para falsas interpretações ou abusos. Seria uma porta aberta para que os próprios complexos indomáveis do analista pudessem atuar. A técnica poderia ser usada como uma resistência do analista, assim como uma forma de satisfazer desejos inconscientes deste. Por isso, Ferenczi (2011e) salienta que a capacidade de "sentir com" do analista só é possível a partir de um analista bem analisado. Segundo ele,

"A única base confiável para uma boa técnica analítica é a análise terminada do analista. É evidente que num analista bem analisado, os processos de "sentir com" e de avaliação, exigidos por mim, não se desenrolarão no inconsciente, mas no nível préconsciente". (FERENCZI, 2011e, p. 42).

Ao mesmo tempo, Ferenczi (2011e) reforça que todos os analistas que não possuem tato usariam este conceito técnico como forma de justificar o 
arbitrário ou o fator subjetivo, que na realidade, seriam manifestações do inconsciente não analisado do analista.

Por isso, quando Ferenczi propõe a elasticidade da técnica e o compartilhar afetivo entre paciente e analista, não quer dizer que este esteja autorizado a uma identificação com o paciente. Pelo contrário, o analista deve estar consciente do que se refere ao paciente e o que está associado aos seus próprios complexos, para assim evitar o risco de projetar os próprios conteúdos psíquicos no paciente. Podese dizer que uma análise conforme proposta por Ferenczi exige do analista, além de uma verdadeira disponibilidade afetiva, sua própria análise. Esta não se confunde com uma análise didática institucionalizada, mas uma verdadeira análise do analista, que o permitirá estar de frente com seus aspectos mais profundos do inconsciente. Só é capaz de exercer a psicanálise, o analista que tiver sido analisado. No entanto, vale frisar que o analista, por mais que faça sua própria análise, não chegará ao fim da mesma, pois sempre estarão presentes conteúdos inconscientes, impossíveis de serem decifrados.

Racker (1982) vai utilizar o "mito da situação analítica" para destacar a importância da análise contínua do analista. Segundo o mito, a análise se dá entre um indivíduo doente e um são. Este é um mito! O que ocorre na situação analítica é o encontro entre duas personalidades, com seus respectivos id, ego, superego, seus mundos externos e internos, seus lados infantis. Portanto, sair pela "objetividade" ou pelo "fundir-se" corresponde a respostas neuróticas do analista. A frieza da suposta objetividade assim como o sofrer e reviver fundido com o paciente representa a permanência no círculo vicioso da neurose. Qual é a saída? Para Racker é a capacidade do analista de se tornar como objeto de sua observação e análise contínua. Para Racker 1982), "Esta posição capacita-o, também, a ser relativamente "objetivo" com o paciente." (RACKER, 1982, p. 125).

\section{Considerações Finais}

Ambos os autores, Freud e Ferenczi, demonstraram em seus escritos a importância da relação analista e analisando, como forma de mudança ou como obstáculo ao tratamento. Ferenczi enfatizou a capacidade de amar do analista; Freud destacou a capacidade de analisar do analista.

Dizer que o analista precisa reviver o trauma com o paciente, que precisa ser empático, ou que deve sentir com, pouco resolve. O analista, quando for capaz de viver o objeto de amor ou de ódio de seu paciente, poderá abrir a porta da rememoração.

Cabe ao analista realizar sua própria análise, para abrir a possibilidade de refletir o paciente, com a menor interferência possível com o que vem do analista. Não o analista como um espelho frio, mas aquele capaz de exercer a função de espelho, que capacita o sujeito de se reconhecer e construir sua identidade. O analista sente com o paciente, identifica-se com ele, mas consciente destas identificações. Isto permite a compreensão do analista, não a compreensão teórica, mas a possibilidade de transmitir ao paciente a possibilidade de ser compreendido.

\section{Referências}

FÉDIDA, P. Clínica psicanalítica: estudos. São Paulo: Escuta, 1988.

FERENCZI, S. A técnica psicanalítica. In: DUPONT, J. (Ed.). Obras completas de Sándor Ferenczi: psicanálise II. São Paulo: M. Fontes, 2011a. p. 407-419.

. Adaptação da família à criança. In: DUPONT, J. (Ed.). Obras completas de Sándor Ferenczi. Psicanálise IV. São Paulo: M. Fontes, 2011b. p. 1-15.

. Análises de crianças com adultos. In: DUPONT, J. (Ed.). Obras completas de Sándor Ferenczi. Psicanálise $I V$. São Paulo: M. Fontes, 2011c. p.79-95.

. Confusão de língua entre os adultos e a criança. In: DUPONT, J. (Ed.). Obras completas de Sándor Ferenczi: psicanálise IV. São Paulo: M. Fontes, 2011d, p. 111-121. 
. Elasticidade da técnica psicanalítica. In: DUPONT, J. (Ed.). Obras completas de Sándor Ferenczi: psicanálise IV. São Paulo: M. Fontes, 2011e. p. 29-42.

. O problema do fim da análise. In: DUPONT, J. (Ed.). Obras completas de Sándor Ferenczi: psicanálise IV. São Paulo: M. Fontes, 2011f. p. 17-27.

FREUD, S Análise terminável e interminável (1937). In: _. Moisés e o monoteísmo três ensaios. Rio de Janeiro: Imago, 1996c. p. 223-270. (Edição Standard Brasileira das Obras Psicológicas Completas de Sigmund Freud, v. 23).

. A dinâmica da transferência (1912). In:

$\bar{O}$ caso de Schreber e artigos sobre técnica. $\overline{\text { Rio de }}$ Janeiro: Imago, 1996a. p. 107-120. (Edição Standard Brasileira das Obras Psicológicas Completas de Sigmund Freud, v. 12).

. Além do princípio de prazer (1920). In:

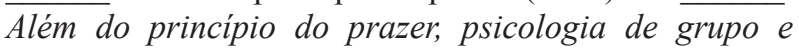
outros trabalhos. Rio de Janeiro: Imago, 1996b. p. 1175. (Edição Standard Brasileira das Obras Psicológicas Completas de Sigmund Freud, v. 18).

. Esboço de psicanálise (1940). In:

Moisés e o monoteísmo três ensaios. Rio de Janeiro: Imago, 1996d. p. 151-222. (Edição Standard Brasileira das Obras Psicológicas Completas de Sigmund Freud, v. 23).

O inconsciente (1915). In: . O ego e o ID

e outros trabalhos. Rio de Janeiro: Imago, 1996e. p. 163209. (Edição Standard Brasileira das Obras Psicológicas Completas de Sigmund Freud, v. 14).
. Observações sobre o amor transferencial (1915). In: $\quad$ O caso de Schreber e artigos sobre técnica. Rio de Janeiro: Imago, 1996f. p. 173-188. (Edição Standard Brasileira das Obras Psicológicas Completas de Sigmund Freud, v. 12).

. Recordar, repetir e elaborar (1914). In:

O caso de Schreber e artigos sobre técnica. Rio de Janeiro: Imago, 1996h. p. 159-172. (Edição Standard Brasileira das Obras Psicológicas Completas de Sigmund Freud, v. 12).

KUPERMANN, D. Presença sensível: a experiência da transferência em Freud, Ferenczi e Winnicott. Jornal de Psicanálise, São Paulo, v. 41, n. 75, p. 75-96, 2008.

PONTES, A. R. N.; TORRANO, L. M. A comunicação inconsciente interpsíquica (paciente/analista) segundo o modelo Bluetooth na psicanálise. Revista de Psicanálise da Sociedade de Psicanálise de Ribeirão Preto, Ribeirão Preto, v. 1 n. 1, p. 37-49, 2010.

RACKER, H. Estudos sobre técnica psicanalítica. Porto Alegre: Artes Médicas, 1982.

RESNIK, S. Le contre-transfert. Journal de la Psychanalyse de l'Enfant, Paris, n. 6, p. 182-196, 1989.

SANCHES, G. P. Freud Sigmund e Sándor Ferenczi. In: FIGUEIRA, S. A. (Org.). Contratransferência: de Freud aos contemporâneos. São Paulo: Casa do Psicólogo, 1994, p.33-59.

THIS, B. Introdução à obra de Ferenczi. In: NASIO, J.D. (Org.). Introdução às obras de Freud, Ferenczi, Groddeck, Klein, Winnicott, Dolto. Rio de Janeiro: Zahar, 1995, p.59-101. 